\title{
NONLINEAR DEGENERATE DIFFUSION PROBLEMS WITH A SINGULARITY
}

\author{
KAOUTHER AmMAR AND Hicham REDWANE
}

Abstract. We consider a class of degenerate nonlinear diffusion problems with a singularity in a finite value $M>0$ of the unknown $v$. For such problems, we introduce a notion of renormalized entropy solution which (under a particular "growth" assumptions on the diffusion term) can reach the value $M$. We prove the existence of such a solution for the stationary equation with $L^{1}$ data.

Mathematics subject classification (2010): 35J60, 35K35, 35K55.

Keywords and phrases: degenerate, homogenous boundary conditions, renormalized entropy solution, continuous flux, integrable data.

\section{REFERENCES}

[1] H. W. Alt And S. Luckhaus, Quasilinear elliptic-parabolic differential equations, Math. Z., 183 (1983), 311-341.

[2] M. Bendahmane And K. H. KARlsen, Renormalized entropy solutions for quasi-linear anisotropic degenerate parabolic equations, SIAM J. Math. Anal., 36, 2 (2004), 405-422.

[3] K. AmmaR, On nonlinear diffusion problems with strong degeneracy, J. Differential Equations, 244, 8 (2008), 1841-1887.

[4] K. AMMAR, Renormalized entropy solutions for degenerate nonlinear evolution problems, Electron. J. Differential Equations, 147 (2009), 1-32.

[5] K. AMmaR, On nonuniformly elliptic degenerate problems, submitted for publication.

[6] K. Ammar, J. CARRILlo AND P. Wittbold, Scalar conservation laws with general boundary condition and continuous flux function, J. Differential Equations, 228 (2006), 111-139.

[7] K. Ammar And H. Redwane, Degenerate stationary problems with homogeneous boundary conditions, Electron. J. Differential Equations, 30 (2008), 1-17.

[8] K. AmmaR AND P. Wittbold, On a degenerate scalar conservation law with general boundary condition, Differential Integral Equations, 21, 3-4 (2008), 363-386.

[9] K. AMMAR AND P. WitTBOLD, Existence of renormalized solutions of degenerate elliptic-parabolic problems, Proc. Roy. Soc. Edinburgh Sect. A, 133, 3 (2003), 477-496.

[10] C. Bardos, A.Y. LeRouX AND J.C. Nedelec, First order quasilinear equations with boundary conditions, Comm. Partial Differential Equations, 4, 9 (1979), 1017-1034.

[11] Ph. Bénilan, J. CarRillo And P. Wittbold, Renormalized entropy solutions of scalar conservation laws, Ann. Scuola Norm. Sup. Pisa Cl. Sci., 29 (2000) 313-329.

[12] Ph. BÉnilan, M.G. Crandall And A. PaZy, Nonlinear evolution equations in Banach spaces, in preparation.

[13] P. Bénilan, B. Boccardo, T. Gallouét, R. Gariephy, M. Pierre and J.L. Vazquez, An $L^{1}$-theory of existence and uniqueness of solutions of nonlinear elliptic equations, Ann. Scuola Norm. Sup. Pisa Cl. Sci., 22 (1995), 241-273.

[14] D. Blanchard, O. GuiBÉ, Infinite valued solutions of non-uniformly elliptic problems, Anal. Appl. (Singap.), 2, 3 (2004), 227-246.

[15] D. Blanchard, O. Guibé and H. Redwane, Nonlinear equations with unbounded heat conduction and integrable data, Ann. Mat. Pura Appl. (4), 187, 3 (2008), 405-433.

[16] D. Blanchard and A. Porreta, Stefan problems with nonlinear diffusion and convection, J. Differential Equations, 210 (2005), 383-428. 
[17] J. CARRILlo, Entropy solutions for nonlinear degenerate problems, Arch. Ration. Mech. Anal., 147 (1999), 269-361.

[18] J. CARRILlo AND P. WittBold, Uniqueness of renormalized solutions of degenerate ellipticparabolic problems, J. Differential Equations, 156 (1999), 93-121.

[19] J. CARRILLO AND P. WitTBOLD, Renormalized entropy solutions of scalar conservation laws with boundary condition, J. Differential Equations, 185 (2002), 137-160.

[20] R. DiPerna, Measure-valued solutions to conservation laws, Arch. Ration. Mech. Anal., 88 (1985), 223-270.

[21] R. Eymard, R. Herbin AND A. Michel, Mathematical study of a petroleum engineering scheme, M2AN Math. Model. Numer. Anal., 37, 6 (2003), 937-972.

[22] T. GALlOUËT, Boundary conditions for hyperbolic equations or systems, Numerical mathematics and advanced applications, Springer, Berlin, 2004.

[23] E. Giusti, Minimal Surfaces and Functions of Bounded Variation, Monographs in Mathematics, Birkhäuser, 1984.

[24] K. H. Karlsen, K. H. Risebro And N. H. Towers, On a nonlinear degenerate parabolic transport-diffusion equation with a discontinuous coefficient, Electron. J. Differential Equations, $\mathbf{9 3}$ (2002), 1-23.

[25] K. H. KARLSEN AND N. H. Towers, Convergence of the Lax-Friedrichs scheme and stability for conservation laws with discontinuous space-time dependant flux. Preprint series. Pure Mathematics, Dept. of Math. University of Oslo, 13, 2004.

[26] R. Eymard, T. GallouËt And R. Herbin, Finite Volume Methods, Handb. Numer. Anal., VII, North-Holland, Amsterdam, 2000.

[27] J.-L. Lions, Quelques méthodes de résolution des problèmes aux limites non linéaire, Dunod et Gauthier-Villars Paris, 1969.

[28] S. N. KRUZHKOV, Generalized solutions of the Cauchy problem in the large for first-order nonlinear equations, Dokl. Akad. Nauk. SSSR, 10 (1969), 29-32.

[29] S. N. KRUZHKOV, First order quasilinear equations in several independent variables, Mat. Sb. (N.S.), 81 (1970), 228-255.

[30] F. MURAT, Soluciones renormalizadas de EDP elipticas non lineales, Technical Report R93023, Laboratoire d'analyse Numérique, Paris VI, Cours à l'Université de Séville, 1993.

[31] F. Oтто, Initial-boundary value problem for a scalar conservation law, C. R. Acad. Sci. Paris Sr. I Math., 322 (1996), 729-734.

[32] A. Porretta AND J. Vovelle, $L^{1}$-solutions to first-order hyperbolic equations in bounded domains, Comm. Partial Differential Equations, 28 (2003), 381-408.

[33] A. Michel AND J. VovelLE, Entropy formulation for parabolic degenerate equations with general Dirichlet boundary conditions and application to the convergence of FV methods, SIAM J. Numer. Anal., 41, 6 (2003), 2262-2293. 